\title{
Effect of Light Emitting Diodes (LED) with 430-480 nm Wavelength Upon Tooth Movement
}

\author{
Chalumporn Ubolviroj ${ }^{1}$, Chulaluk Komoltri ${ }^{2}$, Somchai Manopattanakul ${ }^{3}$ and Nita Viwattanatipa*4 \\ ${ }^{1}$ Orthodontic Department, Mahidol University, Thailand \\ ${ }^{2}$ Faculty of Medicine, Mahidol University, Thailand
}

${ }^{3}$ Department of Advanced General Dentistry, Mahidol University, Thailand

${ }^{4}$ Department of Orthodontics, Mahidol University, Thailand

Received: 㠿: October 16, 2018; Published: 眥: October 25, 2018

*Corresponding author: Nita Viwattanatipa, Department of Orthodontics, Faculty of Dentistry, Mahidol University, Thailand

\begin{abstract}
Objective: To evaluate whether light emitting diodes (LED) curing light had any effect upon orthodontic tooth movement.

Material and Methods: Randomization, split mouth technique and double-blind trial was performed in 20 adults, Angle's Class I or II, patients. Canine retraction into upper first premolar extraction using Niti coil spring was performed. Either LED (3M Elipar S10 with intensity of $1200 \mathrm{~mW} /$ $\mathrm{cm}^{2}$ wavelength range $430-480 \mathrm{~nm}$ ) was applied every 3 weeks or placebo on control side. Three digital panorex were taken with calibrated wire at the start of retraction and after retraction every 9 weeks interval. Measurement of canine tooth movement was done by synapse program on digital panorex and rate of canine tooth movement was gathered at the end of phase 1, phase 2 and total time (18 weeks). Rate of tooth movement, canine angulation changes and score of pain level were contrasted using matched paired T test phase 1.
\end{abstract}

Results: Average rate of canine tooth movement for LED VS. control group; in phase I was 0.32 and $0.33 \mathrm{~mm} /$ week, in phase 2 was 0.25 and $0.22 \mathrm{~mm} /$ week, and in total time was 0.28 and $0.27 \mathrm{~mm} /$ week respectively. In all 3 phases there were no statistical difference in the rate of canine movement or canine angulation change between the LED and control groups. VAS pain score revealed that patients were more sensitive on the LED side than control side.

Conclusion: LED light with 430-480 nm wavelength could not accelerate the rate of canine tooth movement into extraction site.

Keywords: Randomized Clinical Trial; Light Emitting Diodes; Led Curing Light; Accelerated Tooth Movement; Orthodontics

\section{Introduction}

Two basic ways to reduce the orthodontic treatment duration or accelerating orthodontic tooth movement (AOTM) could be classified into 2 categories;

a) Surgical invasive method and

b) Non-surgical invasive method [1]. The invasive procedures were associated with postoperative morbidity and harmful effects on periodontal tissues; thus the patient's acceptance of the procedure was low.

Non-invasive method seems to be a more promising technique because it provided many advantages, for example, easy access, better experience for patients, withoutsurgical complications. These techniques include; electrical currents [2] resonance vibration [3] pulsed electromagnetic fields [4] pharmacological approaches [5] and photo biomodulation [6, 7]. Photo biomodulation is a system using various light sources either lasers or light emitting diodes (LED) with different parameters (wavelength, output power, continuous wave or pulsed operation modes, pulse parameters) to stimulate natural biological processes in order to reduce treatment time [8]. Light in the red to near infrared wavelengths around 630$1000 \mathrm{~nm}$ have been found to be the best penetration into tissue and activates intra-cellular signaling mechanisms [9]. The mechanisms may include

a) Activation of mitochondrial photo acceptor molecule; cytochrome c oxidase to increase ATP production, nitric oxide and very low levels of reactive oxygen species [9-11] or

b) Capillary dilatation to increase blood flow and osteoclastic activity [12]. 
Compared to lasers, LEDs are non-coherent, safer, and less expensive. So far, there were only a few clinical studies about LEDs inducing AOTM. Most of them used LED devices developed by Biolux research, Canada. There were mainly 2 types of devices.

a) Extra-oral type $[7,11,13]$ and b) Intra-oral type [14] Wave length of $618-850 \mathrm{~nm}$ with the energy intensity ranging from $0.92 \mathrm{~J} / \mathrm{cm} 2$ to $216 \mathrm{~J} / \mathrm{cm}^{2}$ was used by 3 studies who used extraoral device, using intra-oral device [14] AOTM by LED light is non-invasive treatment and less aggressive than Laser. If this method can really accelerate OTM, it might be recommended for orthodontic practices. However, the results of AOTM of these reports were contradicting. Three studies reported significant positive results [7, 11, 14] while Chung et al [13] found no significant result for AOTM in retraction phase using extraoral device. However, equipment to generate the light in red to near infrared range (630-1000 nm) was not practically used in dental clinic due to high cost and evidence is still insufficient. Recently, the situation was even more confusing because there were some dentists talking about using LED curing light to accelerate OTM. So far, there was no study reported about using low wave length of the blue light for AOTM. Our research question was related to the effect of LED curing light upon orthodontic tooth movement. The objective of this randomized controlled trial study was to compare the rate of canine tooth movement into upper first premolar extraction case between the intraoral LED curing light with 430-480 nm wavelength and the control groups.

\section{Materials and Methods}

Prior to participant recruitment, this trial was reviewed and approved by institutional Review Board (IRB). Certificate of approval was granted by Faculty of Dentistry/ Faculty of Pharmacy, Mahidol University: COA.No.MU-DT/PY-IRB 2016/011.1102. Our clinical study comprised 2 parts as follows.

LED Heat Test: In order to ensure patient safety, LED light curing unit (3M Elipar S10) with intensity of $1200 \mathrm{~mW} /$ $\mathrm{cm}^{2}$, wavelength range of 430-480 $\mathrm{nm}$ was tested for heat generated at specific distance of $0,3,5 \mathrm{~mm}$ and at duration of $5,10,15,20$ seconds by using digital thermometer (Thomas Scientific Inc, USA) The changing temperature was measured 3 times per distance and average values were calculated.

\section{Canine Movement Randomized Clinical Trial}

Clinical Registry: Our research was granted clinical registry reference number: ISRCTN96521746 by the International Standard Randomised Controlled Trial Number. Twenty-one volunteers were recruited from the Orthodontic clinic of Mahidol University according to IRB protocol.

a) Inclusion Criteria

i) Adult patients age $\geq 18$ years old

ii) Angle's Class I or II, with upper anterior teeth proclination and protrusion. iii) Crowding less than $2 \mathrm{~mm}$.

iv) Treatment required full fixed edgewise appliance therapy of all permanent teeth, with bilateral symmetrical extraction of upper first premolar teeth.

b) Exclusion Criteria

i. Presence of systemic illnesses or bone diseases.

ii. Current exposure to any medical or dental condition that could potentially affect study results such as using of bisphosphonates.

iii. Pregnancy.

iv. Patients planning to relocate or move during the treatment period.

Participants were informed of the study design and were also asked to provide written consent.

\section{Sample Size Calculation}

Based on results of previous study by Ekizer et al. [11] using the following data

Group 1: Mean (M): 1.37 / Standard deviation (s):0.79 / Sample size (n):20

Group 2: Mean (M): 1.13/ Standard deviation (s):1.11 Sample size $(\mathrm{n}): 20$

The effect size: Cohen's d $=(1.13-1.37) / 0.963379=0.25$

Standard Deviation of the change in the outcome $S(\Delta)=0.4$

(calculated from standard deviation $=0.79 /$ within-subject correlation of the outcome $=0.87$ ) The sample size was determined by two dependent means ( $\sigma=0.25, \Delta=0.4, \alpha=0.05, \beta=0.2$ )

Group size N calculated for paired T-test is equal to 20 .

\section{Randomization}

Randomization using random number table and split mouth technique were used to allocate the side of the maxillary teeth (left and right sides) to be the LED or the placebo sides. The protocol is presented in CONSORT diagram (Figure 1). Double trial-blind method was used. One researcher (CU) controlled the assignment of the LED and placebo and the allocation concealment of the LED and placebo side. The LED probe was covered with a foil sheath in placebo side, however the foil sheath at the end of probe was left exposed in LED side. The operator (NV) used LED protective eyeglasses to prevent identification of the method used.

\section{Orthodontics Protocol}

The full arch set-up using pre-adjusted edgewise appliances $0.022 \times 0.028$ slot $\left(\mathrm{MBT}^{\mathrm{TM}}, 3 \mathrm{M}\right.$ Unitek, USA) was the same on both the LED and placebo sides. Four weeks after initial aligning and leveling, bilateral first premolars were extracted. Anchorage was prepared by ligation of second premolar, first and second molars. The maxillary canines were retracted distally on $0.016 \times 0.022$ SS. A light NiTi closed coil spring ligating between canine and first molar 
was used to retract each canine posteriorly to give an initial force of 200 grams as measured by orthodontic tension gauge (Figure 2).
The force was activated every 6 weeks by reactivating the spring tension to $200 \mathrm{~g}$ setting.

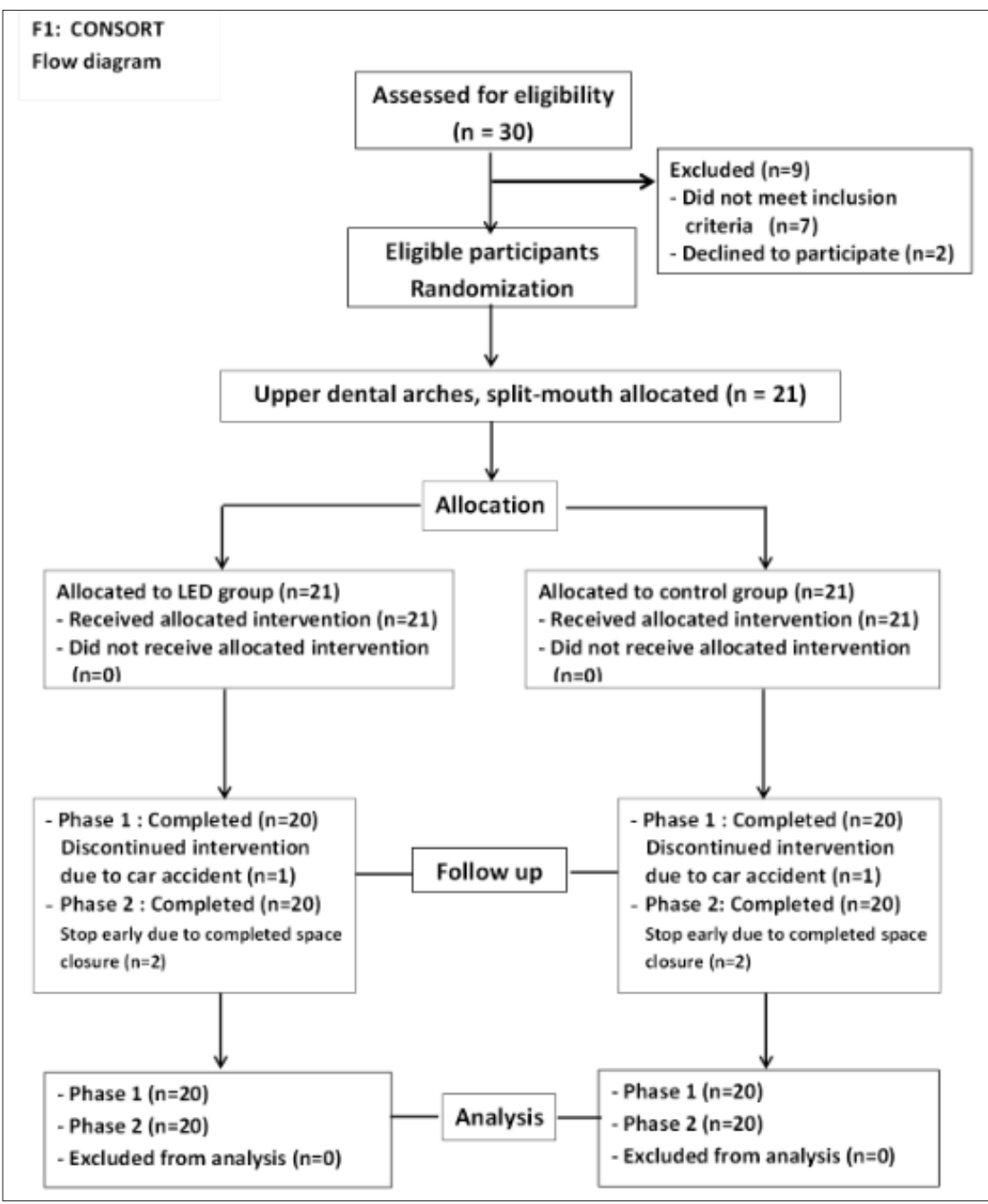

Figure 1: Consort Diagram.

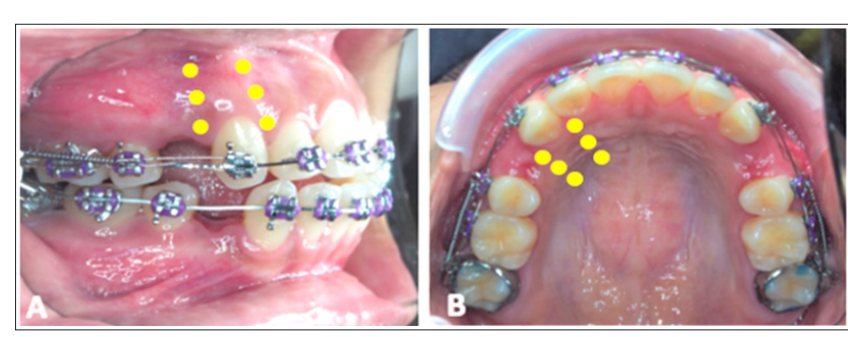

Figure 2: Canine retraction using NiTi closed coil spring.

A. LED application on buccal side.

B. LED application on palatal side.

\section{LED Protocol}

Canine on 1 side was subjected to LED intervention while the other side (No LED) was used as placebo control. The LED dental curing light device (Elipar ${ }^{\mathrm{TM}}$ S10, 3M ESPE, USA) with energy output $1200 \mathrm{~mW} / \mathrm{cm}^{2}$, Energy intensity $6 \mathrm{~J} / \mathrm{cm}^{2}$, wavelength range 430-
$480 \mathrm{~nm}$ was used. Dental curing lights was tested using radiometer for determining the light intensity prior to light application. LED application was made around canine root 6 points buccally and 6 points lingually, 5 seconds per point at distance $3 \mathrm{~mm}$ from gingiva (Figure 2). LED was applied every 3 weeks for 7 times. LED curing light characteristics are presented in Table 1.

Table 1: LED setting.

\begin{tabular}{|c|c|}
\hline \multicolumn{2}{|c|}{ LED setting } \\
\hline LED type/brand & Elipar $^{\text {TM }}$ S10 , 3M \\
\hline Wave length $(\mathrm{nm})$ peak & $430-480 \mathrm{~nm}$ \\
\hline Energy output $(\mathrm{mW})$ & $1,200 \mathrm{~mW} / \mathrm{cm}^{2}$ \\
\hline Energy intensity $\left(\mathrm{J} / \mathrm{cm}^{2}\right)$ & $6 \mathrm{~J} / \mathrm{cm}^{2}$ \\
\hline Exposure time $(\mathrm{sec})$ & $5 \mathrm{sec} / \mathrm{point}$ \\
\hline Protocol/How many point per cycle & 12 points \\
\hline
\end{tabular}




\begin{tabular}{|c|c|}
\hline Location apply: canine & $\begin{array}{c}\text { Mesial / Distal } \\
\text { Buccal / Palatal } \\
\text { Apical/ Middle/ Cervical }\end{array}$ \\
\hline Frequency/cycles & $\begin{array}{c}\text { Initial Levelling } \\
\text { Canine retraction: every } 3 \\
\text { weeks }\end{array}$ \\
\hline Distance LED Tip - Gingiva & 3 mm from gingiva \\
\hline Total duration (months) & 4.5 months \\
\hline
\end{tabular}

\section{Radiographs Protocol}

At the first visit for Orthodontic record and treatment plan, participants had x-ray panoramic, lateral cephalometric and full mouth parallel radiographs taken. During research, digital panoramic radiographs was recorded 3 times. First time, at the start of canine retraction and then every 9 weeks later. Calibrated measuring wires of $15 \mathrm{~mm}$. in length were ligated to brackets on both sides prior to radiographs taken. These calibrated measuring wires would be used to adjust for magnification distortion inherent in panoramic films. The rate of canine tooth movement was gathered for 3 intervals; phase 1 (3-12 weeks), phase 2 (12-21 weeks and total time (3-21 weeks). Operator performed blinded assessment of canine tooth movement, not knowing the side of LED nor Placebo. Digital measurements was carried out using the Synapse program (PACSDTMU, version 1.0, Fujifilm, Tokyo). The measurements included were as follows.

a) Distance between distal aspect of canine bracket to mesial aspect of first molar bracket.

b) Canine tooth axis angulation to palatal plane was measured in order to determine type of canine tooth movement. Calibrated measuring wires was used to adjust for the actual distance of canine movement from digital panoramic radiograph. Actual canine tooth movement was then calculated using the below formula canine tooth movement per week was then calculated using the below formula (Figure 3).

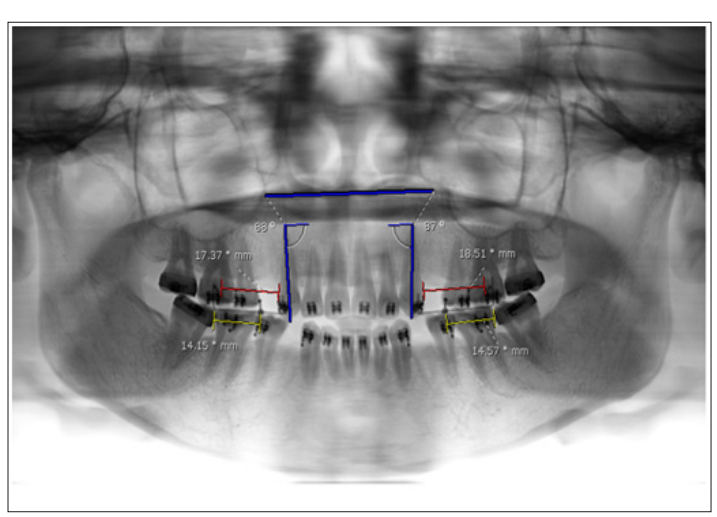

Figure 3: Measurement of canine tooth movement and tooth angulation from digital panoramic radiograph using Synapse program.

Actual tooth movement $=(X-$ ray tooth movement $\times 15 \mathrm{~mm}) /$ X-ray wire length

\section{Complications of Treatment}

Parallel films and Electric pulp vitality testing (EPT) were taken before and after treatment to identify root resorption and pulp vitality [15] Classification of root resorption was based on the method used by Levander and Malmgren classification in 1988 [16] The grading of root resorption could be classified as

Grade $1=$ minimal resorption (irregular apical contour), Grade $2=$ moderate $(<2 \mathrm{~mm})$, Grade $3=$ severe resorption $(>2 \mathrm{~mm}<1 / 3$ root) and Grade $4=$ extreme resorption ( $>1 / 3$ root).

\section{Pain Assessment}

Every visit, after application of LED curing light for 7 times, the volunteers were asked to rate their pain level in LED side and control side by using numerical rating scale (NRS) sheet with scores $1-10(0=$ no pain, $1-3=$ mild pain, $4-6=$ moderate pain, 7-10 = severe pain). Summary of overall treatment protocol and method of data collection are presented in Table 2 .

Table 2: Orthodontic treatment protocol and method of data collection.

\begin{tabular}{|c|c|c|c|c|c|c|}
\hline Week & $\begin{array}{c}\text { Treatment plan } \\
\text { proposal }\end{array}$ & $\begin{array}{c}\text { Invitation to } \\
\text { participatio } \\
\mathbf{n} \\
\text { (LED) }\end{array}$ & Pain (NRS) & $\begin{array}{c}\text { x-ray } \\
\text { Panorami } \\
\text { c }\end{array}$ & $\begin{array}{c}\text { Vitality } \\
\text { test }\end{array}$ & $\begin{array}{l}\text { Periapical } \\
\text { film }\end{array}$ \\
\hline & Pre-treatment & & & 2 & & 2 \\
\hline & Banding / Bonding & & & & & \\
\hline & Refer extraction & & & & & \\
\hline 0 & Leveling & 1 & 2 & & 2 & \\
\hline 3 & 1 Canine retraction & 2 & 2 & $1 *$ & & \\
\hline 6 & & 3 & 2 & & \multirow{2}{*}{$\begin{array}{l}\text { Phase I } \\
9 \text { week }\end{array}$} & \\
\hline 9 & 2 Canine retraction & 4 & $\sqrt{2}$ & & & \\
\hline 12 & & 5 & 2 & $2 *$ & & \\
\hline 15 & 3 Canine retraction & 6 & 2 & & \multirow{2}{*}{$\begin{array}{l}\text { Phase II } \\
9 \text { week }\end{array}$} & \\
\hline 18 & & 7 & $\sqrt{2}$ & & & \\
\hline 21 & Final & & & $3^{*}$ & 2 & 2 \\
\hline
\end{tabular}




\section{Statistical Analysis}

Data were analysed using PASW 18.0. Shapiro-Wilk test was used to indicate normal distribution of data. Shapiro-Wilk Test showed normal distribution (p-valve of LED phase1, phase 2, total time $=0.159,0.943,0.471, p$-valve of Control phase 1 , phase 2 , total time $=0.338,0.244,0.978$ ). Paired t-test was used to compare the rate of canine tooth movement (mm/week) in 3 parts (phase 1, phase 2 and total time) between LED and control group.

\section{Reliability Test}

Intraclass correlation coefficient (ICC) was calculated to assess intra-observer reliability of 3 groups (calibrated measuring wires, distance of tooth movement and angulation measurement). One orthodontist measured 40 distance and repeated three times per group. ICC estimates and their 95\% confident intervals were calculated based on a mean-rating $(\mathrm{k}=3)$, absolute-agreement, 2 way random-effects model. Poor, good and excellent reliability would correspond to ICC of $<0.4,0.4-0.75$ and $0.75-1.00$ respectively [17].

\section{Results}

\section{LED Heat Test}

When radiated at a longer duration $(5,10,15,20 \mathrm{~s})$, the average temperature was increased. The average temperature was decreased when the light source was put farther away. At duration of 5 seconds, Average heat from LED light increased 1.33 degree $\left(27.33^{\circ} \mathrm{C}\right)$ for all 3 distances $(0,3,5 \mathrm{~cm})$. When radiated duration increased, the temperature increased averagely 1-2 degree per 5 seconds. For safety reasons, duration of 5 seconds at distance of 3 $\mathrm{mm}$. was used in this study.

\section{Canine Movement: Randomized Clinical Trial}

Twenty-one adult participants were recruited in this research. Unfortunately, one participant was dropped off due to the problem of car accident which hindered him to come on appointment. Data of 20 adult participants with average age of $21.1 \pm 3.9$ years old were finally used for analysis. In phase I, average rate of canine tooth movement (mm/week) did not show any significant differences between LED and control side $(0.32 \pm 0.16$ vs. $0.33 \pm 0.11$, p-value $=0.833$ ). Similarly, phase II and total time, the average rate at LED side did not show any significant between groups differences as well (phase II: $0.25 \pm 0.11$ vs $0.22 \pm 0.06$, p-value $=0.309$, total time, $0.28 \pm 0.10$ vs $0.27 \pm 0.06, p$-value $=0.594$ ) (Table 3 ). Almost all canine angulations increased during retraction phase not only in LED side but also in control side. The average increased angulation in LED was $10.9^{\circ}$ and control was $11.6^{\circ}$. There was no significant between groups differences (Table 3 ).

Table 3: Rate of canine tooth movement (mm/week), angulation change of canine tooth (degree) and results of paired T-test.

\begin{tabular}{|c|c|c|c|c|c|}
\hline \multirow{2}{*}{ Treatment phase } & \multicolumn{5}{|c|}{ Rate of canine tooth movement(mm/week) } \\
\hline & LED & SD & Control & SD & P-value \\
\hline Phase 1 & 0.32 & 0.16 & 0.33 & 0.11 & 0.83 \\
\hline Phase 2 & 0.25 & 0.11 & 0.22 & 0.06 & 0.31 \\
\hline Total time & 0.28 & 0.10 & 0.27 & 0.06 & 0.59 \\
\hline \multicolumn{6}{|c|}{ Angulation change of canine tooth (degree) } \\
\hline Phase 1 & 6.8 & 5.6 & 7.6 & 4.5 & 0.54 \\
\hline Phase 2 & 4.1 & 3.9 & 4.0 & 3.7 & 0.93 \\
\hline Total time & 10.9 & 6.6 & 11.6 & 4.5 & 0.61 \\
\hline
\end{tabular}

\section{Complications}

Apical root resorption of retracted canine and tooth vitality was evaluated before and after treatment. Results found that there was no canine root resorption in all teeth except two teeth (one in LED side, the other in control side) which showed Grade 1: minimal resorption and all teeth were vital (positive to EPT test).

\section{Pain Assessment}

Pain score of LED group was significantly higher than placebo group. LED side had significant mean NRS pain score $(3.29 \pm 1.8)$ more than control side $(0.59 \pm 0.61)$. In LED side, participants gave high pain score at 1-3 visits of LED application. In control side participants mostly gave higher score at first visit of LED application and decreased gradually after that.

\section{Power of Test Calculation}

Using the following values for paired data sample type in the online website [18].

Sample size $=20$
Effect size was assessed as:

$\mu 1=$ mean of total time LED group

$\mu 2=$ mean of total time Control group

$\sigma 2=$ common error variance $=0.01$

2 sided test

Significance level $=0.05$

The power achieved was 0.98

\section{Reliability Test}

Excellent agreement (95\% CI) was demonstrated for all groups as follows
a) calibrated measuring wires with ICC $=0.875$
b) Distance of tooth movement with ICC $=0.893$ and
c) Angulation measurement with ICC $=0.948$ 


\section{Discussion}

This study utilized the application of intra-oral LED curing unit (430-480 $\mathrm{nm}$ wavelength, $1,200 \mathrm{~mW} / \mathrm{cm}^{2}, 6 \mathrm{~J} / \mathrm{cm}^{2}$ ) over gingival tissue of upper canine retracted into first premolar extraction site. The protocol of this LED application was 5 seconds per spot, 12 spots per tooth with frequency of once every 3 weeks. The results showed that this LED application did not have any effect upon the rate of canine movement. The methodology of our study was

Table 4: Comparison of LED studies characteristics and results. unlike other LED studies in several aspects (Table 4). Firstly, the wave length was shorter (430-480 nm) compared to other studies (618-850 nm). Our LED was in the range of blue light while other studies was in the range of red light $[7,11,13,14]$. The blue light has a shorter wave length, with higher energy but scatters more easily than other visible light [19]. This fact could be demonstrated by the energy output of LED used in our study was $1200 \mathrm{~mW} / \mathrm{cm}^{2}$ while the LED of other study using the red light had a lower energy output of $20-150 \mathrm{~mW} / \mathrm{cm}^{2}[7,11,13,14]$.

\begin{tabular}{|c|c|c|c|c|c|}
\hline Author-Year & $\begin{array}{c}\text { C.H.Kau et.al [7] } \\
2013 \\
\text { Cohort }\end{array}$ & $\begin{array}{c}\text { Shaughnessy et al. } \\
\text { [14] } 2016 \\
\text { Cohort }\end{array}$ & $\begin{array}{c}\text { Chung et al. [13] } \\
2015 \\
\text { RCT }\end{array}$ & $\begin{array}{c}\text { Ekizer et al. [11] } \\
2016 \\
\text { RCT }\end{array}$ & $\begin{array}{c}\text { Our research } \\
2018 \\
\text { RCT }\end{array}$ \\
\hline Gender(M/F) & Total $=90(21 \mathrm{M} / 69 \mathrm{~F})$ & Total =19 $(6 \mathrm{M}, 13 \mathrm{~F})$ & Total = 11(11M,6F $)$ & Total = 20(7M,13F $)$ & Total = 20(M8, F12) \\
\hline Age (years) & -Mean age = $18(7)$ & Mean age $=13.9(1.7)$ & Mean age $=16.07$ & Mean age $=16.7(1.41)$ & Mean age $=21.1(3.9)$ \\
\hline Stage of ortho Rx & $\begin{array}{l}\text { Incisors Alignment } \\
\text { phase }\end{array}$ & $\begin{array}{l}\text { Incisors Alignment } \\
\text { phase }\end{array}$ & $\begin{array}{c}\text { Canine } / 1^{\text {st }} \text { premolar } \\
\text { retraction }\end{array}$ & Canine retraction & Canine retraction \\
\hline Ext/Non-ext & Non-ext & Non-ext & $\begin{array}{l}\text { Extract first premolar } \\
(12 \text { case) and second } \\
\text { premolar ( } 5 \text { case })\end{array}$ & $\begin{array}{c}\text { Maxillary first } \\
\text { premolars extraction }\end{array}$ & $\begin{array}{c}\text { Maxillary first } \\
\text { premolars extraction }\end{array}$ \\
\hline Laser type/brand & $\begin{array}{l}\text { Extra-oral OrthoPulse } \\
\text { LED, Biolux Research, }\end{array}$ & $\begin{array}{c}\text { PBM device } \\
\text { OrthoPulse }{ }^{\mathrm{TM}}, \text { Biolux } \\
\text { Research, }\end{array}$ & $\begin{array}{l}\text { The Biolux LED device } \\
\text { Biolux Research Ltd., }\end{array}$ & $\begin{array}{l}\text { OsseoPulse LED device } \\
\text { Biolux Research Ltd, }\end{array}$ & $\begin{array}{l}\text { 3M Elipar S10 (3M, } \\
\text { USA) }\end{array}$ \\
\hline Wave length (nm) & $850 \mathrm{~nm}$ & $850 \mathrm{~nm}$ & $850 \mathrm{~nm}$ & $618 \mathrm{~nm}$ & $430-480 \mathrm{~nm}$ \\
\hline Energy output (mW) & $60 \mathrm{~mW} / \mathrm{cm}^{2}$ & $42 \mathrm{~mW} / \mathrm{cm}^{2}$ & $150 \mathrm{~mW} / \mathrm{cm}^{2}$ & $20 \mathrm{~mW} / \mathrm{cm}^{2}$ & $1200 \mathrm{~mW} / \mathrm{cm}^{2}$ \\
\hline $\begin{array}{l}\text { Energy intensity }(\mathrm{J} / \\
\left.\qquad \mathrm{cm}^{2}\right)\end{array}$ & $\begin{array}{l}1.72 \mathrm{~J} / \mathrm{cm}^{2} \\
2.108 \mathrm{~J} / \mathrm{cm}^{2} \\
3.216 \mathrm{~J} / \mathrm{cm}^{2}\end{array}$ & $9.3 \mathrm{~J} / \mathrm{cm}^{2}$ & $\begin{array}{c}0.92-6.92 \mathrm{~J} / \mathrm{cm}^{2} \\
\text { (Intra-alveolar energy) }\end{array}$ & $24 \mathrm{~J} / \mathrm{cm}^{2}$ & $6 \mathrm{~J} / \mathrm{cm}^{2}$ \\
\hline Exposure time (sec) & $\begin{array}{l}(20 \mathrm{~m} / \mathrm{d}) \\
(30 \mathrm{~m} / \mathrm{d}) \\
(60 \mathrm{~m} / \mathrm{w})\end{array}$ & $\begin{array}{c}3.8 \mathrm{~min} \\
\text { (per arch,per day) }\end{array}$ & $\begin{array}{c}21 \mathrm{~min} \\
\text { (one phototherapy } \\
\text { cycle) }\end{array}$ & $(20 \mathrm{~m} / \mathrm{d})$ & $\begin{array}{c}5 \mathrm{sec} / \text { point } \\
12 \text { points/cycle }\end{array}$ \\
\hline Location apply & Cheek (Extra-oral) & intra-oral & Cheek (Extra-oral) & Cheek (Extra-oral) & intra-oral \\
\hline Frequency/cycles & $\begin{array}{l}\text { 1. Daily 2. Daily } \\
\text { 3. weekly }\end{array}$ & Daily & Daily & Daily & $\begin{array}{l}\text { Every } 3 \text { week } \\
\text { Total } 7 \text { cycle }\end{array}$ \\
\hline Outcome measurement & irregularity index & irregularity index & $\begin{array}{c}\text { Amount of canine/ 1st } \\
\text { premolar movement }\end{array}$ & $\begin{array}{c}\text { Amount of canine } \\
\text { movement }\end{array}$ & $\begin{array}{c}\text { Amount of canine } \\
\text { movement }\end{array}$ \\
\hline $\begin{array}{l}\text { Rate of tooth } \\
\text { movement } \\
\text { Test group } \\
\text { Mean (SD) }\end{array}$ & $1.12(1.05) \mathrm{mm} /$ week & $\begin{array}{c}1.27 \mathrm{~mm} / \text { week } \\
48 \text { day(39) }\end{array}$ & $\begin{array}{c}\text { T0-T1 }(17)=-1.6 \mathrm{~mm} . \\
\text { Rate }=0.04 \mathrm{~mm} / \text { day } \\
\text { T1-T2 }(13)=-0.89 \mathrm{~mm} . \\
\text { Rate }=0.05 \mathrm{~mm} / \text { day }\end{array}$ & $\begin{aligned} \mathrm{T} 1-\mathrm{T} 0= & 1.47(0.51) \\
& \mathrm{mm} . \\
\mathrm{T} 2-\mathrm{T} 1= & 1.37(0.79) \\
& \mathrm{mm} . \\
\mathrm{T} 3-\mathrm{T} 2= & 0.93(0.60) \\
& \mathrm{mm} .\end{aligned}$ & $\begin{array}{c}\text { Phase } \mathrm{I}=0.32(0.16) \\
\mathrm{mm} / \text { week } \\
\text { Phase } \mathrm{II}=0.24(0.11) \\
\mathrm{mm} / \text { week } \\
\text { Total time }=0.28 \\
(0.10) \mathrm{mm} / \text { week }\end{array}$ \\
\hline $\begin{array}{l}\text { Rate of tooth } \\
\text { movement } \\
\text { Control group } \\
\text { Mean (SD) }\end{array}$ & $0.49(0.4) \mathrm{mm} /$ week & $\begin{array}{c}0.44 \text { mm/week } \\
104 \text { day(55) }\end{array}$ & 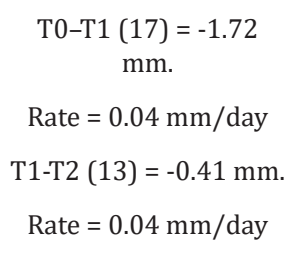 & $\begin{aligned} & \mathrm{T} 1-\mathrm{T} 0= 0.93(0.40) \\
& \mathrm{mm} . \\
& \mathrm{T} 2-\mathrm{T} 1= 1.13(1.11) \\
& \mathrm{mm} . \\
& \mathrm{T} 3-\mathrm{T} 2= 0.71(0.50) \\
& \mathrm{mm} .\end{aligned}$ & $\begin{array}{c}\text { Phase I }=0.33(0.11) \\
\mathrm{mm} / \text { week } \\
\text { Phase II }=0.22(0.06) \\
\mathrm{mm} / \text { week } \\
\text { Total time }=0.27 \\
(0.06) \mathrm{mm} / \text { week }\end{array}$ \\
\hline Significance & Sig & & No sig & Sig & No sig \\
\hline
\end{tabular}


At present, there remains controversy about the effect of LED and appropriate method to apply LED for orthodontic tooth movement. Chung et al [13] found no significant result for accelerating OTM in retraction phase with extra-oral device. Our results were partly in agreement with Chung et al [13] study. On the other hand, 3 studies $[7,11,14]$ using LED wavelength of $618 \mathrm{~nm}-850 \mathrm{~nm}$ with energy intensity ranging from $9.3 \mathrm{~J} / \mathrm{cm}^{2}$ to $216 \mathrm{~J} / \mathrm{cm}^{2}$ reported significant effect upon irregularity index or tooth movement.

Other differences of our LED protocol compared to previous studies were as follows.

a) Our study applied less frequent LED exposure (7 times in 4 month) while other studies demanded daily application by patients.

b) We used shorter exposure time of only 5 seconds while other studies required exposure of 20 - 60 minutes per day. The reason of shorter exposure time was due to the greater heat generated by our LED device. It should be noted that Shaughnessy et al [14] who used intra-oral device of red-light LED had the application time of only 5 minutes per arch per day.

c) LED exposure in our study was intra-orally while most other studies used extra-oral device and applied LED via soft tissue cheeks $[7,11]$. It might be interesting to note that the intra-alveolar energy intensity $\left(0.92-6.9 \mathrm{~J} / \mathrm{cm}^{2}\right)$ as reported by manufacturer of extra-oral device LED was reduced remarkably when compared with the original values [13]. One possible reasons was that the thickness of the cheek had interfered LED light penetration into the alveolar tissue resulting which may result in inadequate energy intensity.

Another different characteristic of blue light and red light was the penetration capacity. Barolet [20] explained that different wavelengths had different chromophores such as blue (400-470 $\mathrm{nm})$, red (630-700 $\mathrm{nm})$ and infrared light (700-1200). The longer the wavelength, the deeper the penetration into tissues. The penetration depth was less than $1 \mathrm{~mm}$ at wavelength of $400 \mathrm{~nm}$ and 1- $6 \mathrm{~mm}$ at wavelength of $630 \mathrm{~nm}$. So, the red light could penetrate deeper in gingiva than blue light and may reach more organism such as mitochondria. Kolte et al [21] demonstrated that the thickness of buccal gingiva in maxillary arch was $1.60( \pm 0.43) \mathrm{mm}$ in 16-24 years and Ramesh et al [22] said that thickness of palatal gingiva was 2.39 (0.99) in 14-21 years. Therefore, the blue light LED used in our study was presumably had less penetration capacity than other red-light LED studies.

LED light activated cytochrome c oxidase in mitochondrial electron transport chain. Horie and Morrison [23] stated that cytochrome c oxidase contains two hemes, cytochrome a and cytochrome a3. Proper absorbed spectrum of cytochrome a was 605-630 nm and cytochrome a3 was 445-460 nm. Although the wave length in our study could hypothetically activated cytochrome a3. There were many other factors why our study did not show statistical difference in the rate of canine tooth movement. For example, specific wavelength range, intensity, penetration capacity, frequency of exposure, timing of exposure [9] So that our blue light LED intervention was not able to penetrate tissue and activated underlying organism that control tooth movement.

The LED protocol in our study did not show any adverse effects. The heat increase of 1.33 degree was considered safe for pulp and periodontal tissue. Kwon SJ et al [24]. reviewed that damage to the tooth-supporting tissues (cementum, periodontal ligament and alveolar bone) could be induced by temperature more than 10 degrees. After 4-month retraction by NiTi coil spring (150-200g) we found no canine root resorption in all teeth but 2 teeth (one in LED side, other in control side) which showed minimal resorption. This root resorption could occur in normal orthodontic tooth movement [25].

Regarding Pain test, NRS was one of the best methods available for pain studies. Results of this research showed that the highest pain intensity peak took place both with the LED and placebo side at the first LED exposure. There was slightly pain reduction after that. Participants did not complain about any discomfort, gingival irritation or pain at next appointment visit. Although control side was not exposed to LED light, participants felt some mild pain. The most common theories used to explain this situation was the placebo effect from person's expectations [26].

\section{Strength}

This study used randomization method. It prevents the selection bias and insures against the accidental bias. It also produced the comparable groups and eliminates the source of bias in treatment assignments. Our RCT, split mouth study met the criteria of randomization, allocation concealment, intent to treat analysis, operator blinded assessment and power calculation. However, patient could not be blinded due to heat generated on the LED side.

\section{Limitations}

Our study measured distance of canine tooth movement from panoramic radiographs. Panoramic technique was quite sensitive to magnification and geometric distortion. Catic et al [27] mentioned that panoramic radiography was an effective method for measuring the liner measurement of vertical, horizontal, oblique and angular variables if it was on only one side of the mandible and if knowing the magnification factor. However, this study tried to resolve this problem by using calibrated measuring wires on both sides to calculate magnification values in each radiograph and measure distances nearest the reference wire for minimal magnification error. Further investigations were warranted to analyze whether the duration, frequency or method of LED exposure would have any effect on the rate of orthodontic tooth movement.

\section{Conclusion}

Intraoral LED light (430-480 $\mathrm{nm}$ wavelength, $6 \mathrm{~J} / \mathrm{cm}^{2}$ ) exposed over gingival tissue had no bio-stimulatory effect to accelerate canine retraction into first premolar extraction site. 


\section{Acknowledgement}

The authors are grateful for the research grant supported by the Faculty of Dentistry, Mahidol University, Thailand.

\section{Conflict of Interest}

Authors do not have any financial interest in the products or information listed in the paper. None to declare.

\section{Ethical Approval}

This trial was reviewed and approved by institutional Review Board (IRB). Certificate of approval was granted by Faculty of Dentistry/ Faculty of Pharmacy, Mahidol University: COA.No.MUDT/PY-IRB 2016/011.1102.

\section{References}

1. Gkantidis N, Mistakidis I, Kouskoura T, Pandis N (2014) Effectiveness of non-conventional methods for accelerated orthodontic tooth movement: a systematic review and meta-analysis. J Dent 42(10): 1300-1319.

2. Davidovitch Z, Finkelson MD, Steigman S, Shanfeld JL, Montgomery PC, et al. (1980) Electric currents, bone remodeling, and orthodontic tooth movement. II. Increase in rate of tooth movement andperiodontal cyclic nucleotide levels by combined force and electric current. Am J Orthod 77(1): 33-47.

3. Nishimura M, Chiba M, Ohashi T, Sato M, Shimizu Y, et al. (2008) Periodontal tissue activation by vibration: intermittent stimulation by resonance vibration accelerates experimental tooth movement in rats Am J Orthod Dentofacial Orthop 133(4): 572-583.

4. Showkatbakhsh R, Jamilian A, Showkatbakhsh M (2010) The effect of pulsed electromagnetic fields on the acceleration of tooth movement. World J Orthod 11(4): e52-e56.

5. McGorray SP, Dolce C, Kramer S, Stewart D, Wheeler TT (2012) A randomized, placebo-controlled clinical trial on the effects of recombinant human relaxin on tooth movement and short-term stability. Am J Orthod Dentofacial Orthop 141(2): 196-203.

6. Cruz DR, Kohara EK, Ribeiro MS, Wetter NU (2004) Effects of lowintensity laser therapy on the orthodontic movement velocity of human teeth: a preliminary study. Lasers Surg Med 35(2): 117-120.

7. Kau CH, Kantarci A, Shaughnessy T, Vachiramon A, Santiwong P, et al. (2013) Photobiomodulation accelerates orthodontic alignment in the early phase of treatment. Prog Orthod 14: 30.

8. Hamblin M, V Pires de Sousa M, Arany P, Patthoff D (2015) Low level laser (light) therapy and Photobiomodulation: The path forward Proc of SPIE 9309930902: 1-11.

9. Kim WS, Calderhead RG (2011) Is light-emitting diode phototherapy (LED-LLLT) really effective? Laser Ther 20(3): 205-215.

10. Eells JT, Wong Riley MT, VerHoeve J, Henry M, Buchman EV, et al. (2004) Mitochondrial signal transduction in accelerated wound and retinal healing by near-infrared light therapy. Mitochondrion 4(5-6): 559-567.

11. Ekizer A, Turker G, Uysal T, Guray E, Tasdemir Z (2016) Light emitting diode mediated Photobiomodulation therapy improves orthodontic tooth movement and miniscrew stability: A randomized controlled clinical trial. Lasers Surg Med 48(10): 936-943.

12. McDonald RS, Gupta S, Maclean M, Ramakrishnan P, Anderson JG, et al. (2013) $405 \mathrm{~nm}$ Light exposure of osteoblasts and inactivation of bacterial isolates from arthroplasty patients: potential for new disinfection applications? Eur Cell Mater 25: 204-214.

13. Chung SE, Tompson B, Gong SG (2015) The effect of light emitting diode phototherapy on rate of orthodontic tooth movement: a split mouth, controlled clinical trial. J Orthod 42(4): 274-283.

14. Shaughnessy T, Kantarci A, Kau CH, Skrenes D, Skrenes S, et al. (2016) Intraoral photobiomodulation-induced orthodontic tooth alignment: a preliminary study. BMC Oral Health 16: 3.

15. Talic NF (2011) Adverse effects of orthodontic treatment: A clinical perspective. The Saudi Dental Journal 23(2): 55-59.

16. Levander E, Malmgren O (1988) Evaluation of the risk of root resorption during orthodontic treatment: a study of upper incisors. Eur J Orthod 10(1): 30-38.

17. Koo TK, Li MY (2016) A Guideline of Selecting and Reporting Intraclass Correlation Coefficients for Reliability Research. J Chiropr Med 15(2): 155-163.

18. (2018) QFAB Bioinformatics. Power calculator for Independent T-test or paired t-test ANZMTG Statistical Decision Tree.

19. Tosini G, Ferguson I, Tsubota K (2016) Effects of blue light on the circadian system and eye physiology. Mol Vis 22: 61-72.

20. Barolet D (2008) Light-emitting diodes (LEDs) in dermatology. Semin Cutan Med Surg 27(4): 227- 238.

21. Kolte R, Kolte A, Mahajan A (2014) Assessment of gingival thickness with regards to age, gender and arch location. J Indian Soc Periodontol 18(4): 478-481.

22. Ramesh Ksv, Swetha P, Krishnan V, Mythili R, Rama Krishna Alla, et al. (2014) Assessment of thickness of palatal masticatory mucosa and maximum graft dimensions at palatal vault associated with age and gender - a clinical study. J Clin Diagn Res 8(5): Zc09-13.

23. Horie S, Morrison M (1963) Cytochrome C oxidase components III. Spectral properties of cytochromes A and A3. J Biol Chem 238: 28592865.

24. Kwon SJ, Park YJ, Jun SH, Ahn JS, Lee IB, et al. (2013) Thermal irritation of teeth during dental treatment procedures. Restor Dent Endod 38(3): 105-112.

25. Weltman B, Vig KW, Fields HW, Shanker S, Kaizar EE (2010) Root resorption associated with orthodontic tooth movement: a systematic review. Am J Orthod Dentofacial Orthop 137(4): 462-476.

26. Haour F (2005) Mechanisms of the placebo effect and of conditioning. Neuroimmunomodulation 12(4): 195-200.

27. Catic A, Celebic A, Valentic Peruzovic M, Catovic A, Jerolimov V, et al. (1998) Evaluation of the precision of dimensional measurements of the mandible on panoramic radiographs. Oral Surg Oral Med Oral Pathol Oral Radiol Endod 86(2): 242-248. 


\section{ISSN: 2574-1241}

DOI: $10.26717 / B J S T R .2018 .10 .001946$

Nita Viwattanatipa. Biomed J Sci \& Tech Res

(c) (P) This work is licensed under Creative

Submission Link: https://biomedres.us/submit-manuscript.php

$\begin{array}{ll}\text { BIOMEDICAL } & \text { Assets of Publishing with us } \\ \text { RESEARCHES } & \text { Global archiving of articles } \\ & \text { - Immediate, unrestricted online access } \\ & \text { - Rigorous Peer Review Process } \\ \end{array}$

